\title{
Estrategia didáctica de aprendizaje basada en inteligencias múltiples predominantes y procesos autorregulatorios en estudiantes rurales de primaria
}

\section{Didactic learning strategy based on predominant multiple intelligences and self- regulatory processes in rural primary school students}

Julio Enrique Tobón Villada

Corporación Universitaria Minuto de Dios-UNIMINUTO, Bogotá, Colombia

jtobovi@uniminuto.edu.co

https://orcid.org/0000-0003-2290-3561

Orlando Marín Buitrago

Corporación Universitaria Minuto de Dios-UNIMINUTO, Bogotá, Colombia orlando.marin@uniminuto.edu.co

\section{https://orcid.org/0000-0003-4155-9620}

Rubén Camilo Tapia Llanos

Corporación Universitaria Minuto de Dios-UNIMINUTO, Bogotá, Colombia ruben.tapia@uniminuto.edu.co

https://orcid.org/0000-0002-5594-6384

Mónica Alexandra Martín García

Corporación Universitaria Minuto de Dios-UNIMINUTO, Bogotá, Colombia monica.martin.g@uniminuto.edu.co

https://orcid.org/0000-0002-1889-6963

Recepción: 10/05/2021 | Aceptación: 28/06/2021 | Publicación: 10/09/2021

Cómo citar (APA, séptima edición):

Tobón Villada, J. E., Marín Buitrago, O., Tapia Llanos, R. C., y Martín García, M. A. (2021). Estrategia didáctica de aprendizaje basada en inteligencias múltiples predominantes y procesos autorregulatorios en estudiantes rurales de primaria. INNOVA Research Journal, 6(3), 34-57.

https://doi.org/10.33890/innova.v6.n3.2021.1751

\section{Resumen}

Esta investigación tuvo como propósito analizar las inteligencias múltiples y las formas de autogestión de los estudiantes del grado $5^{\circ}$ de Básica Primaria en la Escuela Rural Nicolás 
Esguerra de Ibagué - Colombia y diseñar una estrategia didáctica basada en la caracterización de inteligencias múltiples predominantes que optimice el rendimiento académico de los alumnos a través de sus prácticas de autorregulación en el aprendizaje. Este estudio se desarrolló bajo el enfoque metodológico cualitativo, con un diseño fenomenológico de alcance descriptivo, que contó con una unidad informante 13 estudiantes, 7 niños y 6 niñas con edades entre los 9 y 10 años, además de la participación de los padres de familia de los estudiantes y cuatro maestros quienes dieron respuesta a formularios web diseñados con preguntas abiertas y cerradas, así como a una entrevista semiestructurada a uno de los profesores, ambos instrumentos validados por expertos. Los resultados indican que las inteligencias múltiples predominantes en el grupo de análisis son la Ecológica y la Interpersonal y que sus procesos de autorregulación requieren ser fortalecidos en pro de su rendimiento académico. Lo anterior, se constituyó como el principal insumo para que los autores diseñaran una estrategia didáctica innovadora que transversaliza el ámbito curricular de la institución.

Palabras claves: inteligencias múltiples; autorregulación; estrategias didácticas; rendimiento académico; aprendizaje.

\begin{abstract}
This investigation had as a purpose to analyze the multiple intelligences and the forms of selfmanagement of students in the 5th grade of Primary Basic at the Nicolas Esguerra Rural School in Ibague - Colombia and to design a didactic strategy proposal based on the characterization of intelligences predominant multiples that optimize the academic performance of students through their self-regulation practices in learning. This study was developed under the qualitative methodological approach, with a descriptive phenomenological, design that had a nonprobabilistic population sample by convenience of 13 students, 7 boys and 6 girls aged between 9 and 10 years, in addition to the participation of the parents of the students and four teachers who responded to web forms designed with open and closed questions, as well as a semi-structured interview with one of the teachers, both instruments validated by experts. The results indicate that the predominant multiple intelligences in the analysis group are Ecological and Interpersonal and that their self-regulation processes need to be strengthened in favor of their performance. The above was constituted as the main input for the authors to design an innovative didactic strategy that cut across the curricular scope of the institution.
\end{abstract}

Keywords: multiple intelligences; self-regulation; teaching strategies; academic performance; learning.

\title{
Introducción
}

La autorregulación entendida como el proceso activo, constructivo propio y volitivo de los estudiantes, ha tomado protagonismo en el rol que actualmente desempeña dentro del ámbito educativo dado que ha sido concebida como medio y no como fin por las instituciones y los diferentes agentes educativos, en la búsqueda de la mejora en los resultados de aprendizaje y el rendimiento académico de los estudiantes (Schunk, 2012). Dentro de este mismo contexto formativo, se hayan dificultades en los alumnos cuando se sumergen en la búsqueda de resultados en función a la implementación de componentes didácticos relacionados al aprendizaje significativo, lo cual afecta, en muchas ocasiones, su desempeño frente a los procesos de autorregulación o conduce a tener cursos desequilibrados, donde unos avanzan y otros se relegan, 
demandando una mayor intervención de los mediadores y limitando su autonomía (Panadero y Tapia, 2014).

En consecuencia, es necesario conocer la forma en que los procesos de autorregulación se incorporan al diseño de estrategias didácticas en el ámbito escolar de acuerdo con los tipos de inteligencia múltiple de los estudiantes (Valle, 2006). Esto, lleva a centrar la atención en los sucesos propios del educando donde instaura objetivos, planifica, supervisa, controla y regula su motivación, cognición y conducta.

En la literatura, se reitera que para que exista un verdadero aprendizaje, es necesario que se implique la autorregulación en las dimensiones cognitivas y motivacionales; sin embargo, el discurso queda corto sino se trae a colación otro concepto que es necesario ampliar a la luz de nuevas teorías, y este es el de la inteligencia, la cual como lo propone Ardila (2011), se puede entender como una capacidad no limitada a la concepción cuantitativa de objetos medibles, sino como una destreza que tiene todo el potencial de ser desarrollada multidimensionalmente.

De otro lado, el rendimiento académico no siempre tiene que ver precisamente con el promedio de asignaturas aprobadas mediante técnicas estadísticas o cuantitativas, sin importar la incidencia que puedan tener los diferentes factores de carácter personal, social y económico (Jadue, 1997). En este sentido, el rendimiento académico, para propósitos prácticos y operativos de este artículo, será entendido como el conjunto de capacidades, destrezas, hábitos, habilidades e intereses que aplica el educando para aprender, gracias a la implementación de estrategias didácticas de aprendizaje efectivas en función al desarrollo de las inteligencias predominantes del individuo y, en general, del grupo al que pertenezca. Por lo tanto, si el rendimiento académico se considera como el indicador del nivel de aprendizaje que ha alcanzado el estudiante, no deberá ser medido en una sola dirección o dimensión y tal vez tampoco corresponda en toda su extensión a calificaciones numéricas (Edel, 2003).

Por lo anterior, esta investigación busca diseñar una estrategia didáctica de aprendizaje para los tipos de inteligencias predominantes en el grupo de estudiantes del grado $5^{\circ}$ de la Escuela Rural Nicolás Esguerra que promueva la autorregulación y que favorezca su rendimiento académico. Para llegar a este objetivo, primero se caracterizaron los tipos de Inteligencias Múltiples de cada uno de los estudiantes, luego se estableció la relación que tienen las inteligencias múltiples con los procesos de autogestión del aprendizaje de los alumnos y finalmente, se indagó a los docentes sobre las prácticas comúnmente implementadas como insumo para el diseño de la estrategia didáctica.

Este artículo comprende tres grandes secciones: la primera desarrolla la concepción teórica en la que se sustenta la investigación, la segunda presenta el diseño metodológico el cual se estructura desde un análisis cualitativo y por último, se indican los resultados y conclusiones que permitieron llegar a analizar más a fondo las inteligencias múltiples y la autorregulación del aprendizaje para tener los insumos suficientes para diseñar una propuesta de estrategia didáctica que permita mejorar el desempeño académico de los estudiantes. 


\section{Marco teórico}

Para el desarrollo teórico de esta investigación y teniendo como ejes centrales la experiencia docente y la necesidad de encontrar nuevas estrategias acorde con los intereses, desempeños y características de los estudiantes sujetos de estudio, se establece el abordaje de las siguientes tres categorías de análisis: estrategias didácticas de aprendizaje, inteligencias múltiples y procesos de autorregulación.

Respecto a investigaciones previas a este estudio, se han analizado algunos antecedentes de orden nacional e internacional. Uno de los primeros concluyó que, al implementar la teoría y discurso de las inteligencias múltiples en el contexto escolar, se podrá obtener mejores y mayores resultados bajo el marco del desarrollo de los estudiantes, niños y niñas o el género al que se adhieran (Padilla, 2017). Otro antecedente relevante arrojó que, a pesar de las limitantes contextuales aplicar una metodología basada en las inteligencias múltiples en el área de ciencias naturales, potencializó sustancialmente el rendimiento académico y activó procesos autorregulatorios (Martí (2017). Por otro lado, Oliveos (2017) planteó dos conclusiones: las barreras que generan las prácticas educativas de corte tradicionalista hacen que este tipo de ejercicios investigativos sean un reto pedagógico sobresaliente cuando el objetivo es la diversidad e individualidad. Además, que, en general, las inteligencias múltiples sí están siempre presentes en los potenciales cognitivos de los niños y niñas de los distintos niveles educativos. Finalmente, Prada, et al. (2018), permiten evidenciar en su investigación la necesidad de perfilar los intereses de los estudiantes y su predisposición hacia un determinado campo del conocimiento. Eso garantiza una adecuada democratización del proceso de enseñanza - aprendizaje e incrementa las posibilidades de que los estudiantes generen estrategias metacognitivas que fluyen fácilmente, pues está implícita la motivación.

\section{Estrategias didácticas de aprendizaje}

Las estrategias didácticas de aprendizaje, son el conjunto de elementos que un docente pone a disposición de sus estudiantes de forma prevista e intencionada para encaminarlo hacia el aprendizaje (Díaz y Hernández, 2002), además de, contribuir e incentivar a la participación activa tanto del estudiante como del maestro dentro de una esfera de reflexión y proposición pedagógica.

En palabras de Hurtado et al., (2018) la estrategia se concibe como una serie de elementos importantes y secuenciales en la planificación de un ejercicio académico. Estos se seleccionan de manera intencionada, que comprende la elaboración de diferentes fases en el proceso, entre ellos; la planeación, la utilización y la validación de la forma en que las personas pueden llegar a procesar los conocimientos que se proponen en su formación. De otro lado, Delgado y Solano (2011) afirman que la estrategia es un concepto incluyente que contempla tanto el proceso de enseñanza como el de aprendizaje, es decir, es de doble vía. Así, pues, La didáctica vista como ciencia es integradora, socializadora y sistematizadora de conclusiones investigativas y de experiencias que se acumularon en la acción educativa, detecta y proporciona soluciones adecuadas a las problemáticas que tienen incidencia en el desarrollo de la enseñanza y del aprendizaje (Abreu et al., 2017). 
Con respecto al aprendizaje, Asensio (2015) lo reconoce como una característica que tienen los seres vivos a través de la que se generan cambios que transforman de manera perdurable en el tiempo las diferentes conductas y comportamientos, y pueden generar afectaciones importantes tanto individuales como colectivas dentro de contextos locales y globales. Por esta razón, resulta pertinente vincular estos tres conceptos en clave de la pedagogía. Al respecto Gutiérrez y Ones (2018) consideran que, en el campo de la educación, se ha empezado a hablar de estrategia didáctica como una necesidad que ha surgido de la preocupación por las formas de enseñar habitualmente propuestas, pues se deben superar las barreras de lo tradicional y trascender hacia el pensamiento crítico, comprensivo y problematizador de la realidad, empoderando así a los estudiantes en todos los procesos pedagógicos (Tuirán, 2016). Así entonces, se evidencia la necesidad de que haya una conexión con el currículo, el modelo pedagógico y las estrategias didácticas buscando que vayan en la misma dirección.

Por su parte, Espinosa (2016) realiza aproximaciones teóricas al concepto de enseñanza y establece una serie de inferencias importantes asociadas a las estrategias que planifican los profesores. Una de estas es la necesidad de buscar la mediación didáctica como un elemento diferenciador que puede llegar a marcar la pauta en el éxito de los procesos educativos. De esta forma, la formación docente obtiene un papel relevante e invita a tomar un rol activo que lo conduzca a estar replanteando permanentemente sus prácticas (Blanco y Amigo, 2016). A su vez, Hurtado et al., (2018) destacan que un buen diseño de estrategia didáctica genera una respuesta positiva de los estudiantes, conduciéndolos a la adquisición de nuevos aprendizajes y al uso de ellos en contexto, postura que coincide con Seibane et al., (2016) y que además se complementa al indicar que, respecto al rol del estudiante en la aplicación de las estrategias didácticas, se posibilita el aprendizaje significativo y se incrementan sus capacidades cuando se valoran sus conocimientos previos.

Teniendo en consideración las dinámicas de los actores en el proceso educativo, es importante analizar el espacio en que se desarrollan estas acciones de aprendizaje. De ahí que los ambientes de formación se constituyen como otro factor relevante en la construcción de estrategias de aprendizaje, por lo que es recomendable generar las condiciones para que estos se den (Páramo et al., 2015).

\section{Inteligencias múltiples (IM)}

Bestard et al., (2015) definen la inteligencia como la posibilidad de transformación de la experiencia sensorial que se pone en manifiesto a través en una serie de acciones cognitivas complejas. Así mismo, Guilar (2009) indica que esos procesos cognitivos están asociados a las habilidades de clasificación y categorización, inferencia y toma de decisiones, las cuales indican una activación compleja y amplia de redes neuronales. Por otro lado, Gardner (1983) citado por Mercadé (2019), añade que esta capacidad tiene como particularidad que se puede desarrollar progresivamente y su trascendencia es de tipo propositivo y cultural.

Siguiendo este razonamiento, Sesento (2017) hace una amplia e importante revisión teórica del enfoque sociocultural de Vigotsky (1989), en donde describe que la inteligencia es el producto de la interacción directa con el medio sociocultural del contexto y su evolución. Son precisamente 
Estrategia didáctica de aprendizaje basada en inteligencias múltiples predominantes y procesos autorregulatorios en estudiantes rurales de primaria

estos razonamientos los que subyacen a un concepto de inteligencia representativa de la tradición en la que se sitúan las principales investigaciones psicológicas.

La perspectiva cognitivista de la inteligencia donde la acción psicológica y los procesos del cerebro funcionan juntos, fue ampliamente analizada por Piaget (1981), citado por Montealegre (2016), donde argumenta que el desarrollo cognitivo de las personas pasa por un proceso progresivo y en cuyas etapas, el individuo genera una serie de acciones consecutivas que inician desde edad muy temprana hasta llegar a niveles cognitivos superiores o de significaciones, donde el adecuado engranaje del anterior nivel de cognición, conecta y ajusta el siguiente.

Por su parte, Vigotsky (1989) retomado por Montealegre (2016), analiza que, para darle funcionalidad a cualquier acción cognitiva, sea de tipo productiva, del discurso, lógica de la memoria, de aprehensión significativa lingüística o cualquier otra, requiere incorporar los instrumentos de la cultura. En esta misma línea argumentativa, Vivas (2015) revisando la Teoría de las Inteligencias Múltiples (TIM) planteada por Gardner (1983), argumenta que esta no se debe mirar de una manera unidireccional como lo hace el enfoque psicométrico, donde se concibe como una capacidad mental general. Asevera que la inteligencia es multifacética y que el cerebro humano tiene las condiciones para desarrollarlas si se cultivan adecuadamente en los distintos contextos. Identifica ocho clases de inteligencia con sus respectivas particularidades: musical, ecológica, lógico-matemática, lingüística, visual-espacial, intrapersonal, interpersonal y naturalista, (Fernández y Mihura de Rosa (2015), funcionando como la metáfora de los ordenadores donde la afectación de una no implica el daño de todo el sistema (Gardner, 2009). Cada una de estas categorías son necesarias y todo ser humano las desarrolla indistintamente, además la suma de ellas constituye el perfil intelectual de cada persona.

La relevancia de la identificación de las IM descritas anteriormente aplicadas a los contextos educativos, es en consecuencia, una alternativa que potencia el acceso directo al conocimiento y al aprendizaje, maximizando la capacidad implícita en los estudiantes. Armstrong (2017) y Argüelles y Nagles (2009) plantean que estas inteligencias deben ser alimentadas intencionalmente desde todas las combinaciones que sean posibles, especialmente porque los individuos son heterogéneos, lo que permite poner sobre relieve las diversas maneras en que se puede aprender. Lo anterior pone en el centro del proceso los tres vértices del triángulo pedagógico, que es retomado por Klaus (2013), quien citando a Houssaye (1988) explica la relación maestro-estudiante-saber.

Este discurso de las inteligencias múltiples aplicado al contexto educativo, redunda en lo que se denominaría educación integral, dado que lo que se busca es que el estudiante maximice todas sus capacidades y donde se explica que en lugar de considerarse como el resultado de la sumatoria de variables individuales estas se visualizan de manera integrada e interrelacionada (Álvarez, 2003). Es en este sentido, las Inteligencias Múltiples toman una relevancia discursiva que trasciende a la práctica: se aprende desde lo que se domina bien y se desarrolla lo que falta.

\section{Autorregulación del aprendizaje}

García, et al., (2018) citando a Pintrich (2000), plantea que el proceso de autorregulación en el aprendizaje es el conjunto de habilidades que permite controlar los propios pensamientos, 
acciones, emociones y motivaciones. Dicho control se da gracias a la administración por medio de estrategias personales y manejo de las contingencias circunstanciales con el fin de alcanzar los objetivos que previamente se han fijado. Zimmerman (2001) citado por Pandero y Tapia (2014), referencian que un estudiante se encuentra y se autorregula cuando dirige sus esfuerzos al alcance de los objetivos que ha establecido para sí. Valdivia (2017) retomando a Patrick y Middleton (2002), hace énfasis en que la autorregulación del aprendizaje demanda un estudio integrador de todos los aspectos y fases que le componen, coincidiendo en que es un proceso activo, en constante flujo o movimiento y recurrente. Es, además, un acontecimiento individual que opera el alumno a través de su acción pedagógica. Mora et al. (2020).

Al considerar la autorregulación como un proceso, y retomando a Pintrich (2000), se definen cuatro fases: planificación, auto observación, control y evaluación. Así, estas etapas permiten tener una mayor comprensión sobre los saberes, abordándolos de manera más práctica. Si las fases se transversalizan con la motivación como uno de los principales factores intrínsecos que catapultan los aprendizajes autorregulados especialmente si están mediatizados por la acción lúdica y el juego (Recio, 2019), se puede entender que un estudiante puede alcanzar importantes logros en su proceso metacognitivo.

En consecuencia, se analiza que el objetivo de la autorregulación se está cumpliendo cuando se observa al estudiante mejorando su rendimiento académico, adquiriendo aprendizajes significativos, empleando estrategias de control y regularización de aspectos propios de su motivación, intelecto y de su comportamiento, hábitos y rutinas, para poder elegir y construir los entornos de aprendizaje propios y para instaurar objetivos y supervisar su cumplimiento. Panadero (2017) y Candiotti (2017), permiten entender también como objetivo de la autorregulación, el tener individuos monitores de todo su aprendizaje y de forma continua, evaluando, ajustando y gestionando el tiempo de manera eficaz, indagando por recursos, buscando ayuda cuando se necesite y siendo consciente del valor de lo que se aprende.

En suma, las estrategias didácticas vistas desde el aprendizaje, implican un conjunto de variables disponibles que convergen en el firme propósito de lograr que los estudiantes encuentren en la significación el camino y fin hacia la concreción duradera del conocimiento. En este sentido, disponer de un conjunto de estrategias metacognitivas permite que estas se constituyan en puentes que hacen que la trasposición didáctica sea más fácil de producir.

La autonomía, el autocontrol, el automonitoreo y otras estrategias propias de la autorregulación, no pueden ser observadas como acciones fortuitas o accidentales, pues revisadas las perspectivas teóricas, es claro que se hace necesario conducir al estudiante a que sea consciente de su propio aprendizaje, por lo que partir de una identificación real del modo en que se autorregulan, se evidencia cuáles podrían ser las estrategias más convenientes a utilizar. Visto de este modo, explorar las distintas maneras en que el estudiante puede aprender, como lo describe el discurso de las inteligencias múltiples, funciona como un aliado que complementa lo que plantea el discurso de aprendizaje y autorregulación.

Así las cosas, la autorregulación centra su atención especialmente en los factores internos y en las estrategias didácticas de aprendizaje, lo hacen a partir de la reflexión pedagógica, que pueden generar el cómo aprender. La valoración de las inteligencias múltiples democratiza ese 
Estrategia didáctica de aprendizaje basada en inteligencias múltiples predominantes y procesos autorregulatorios en estudiantes rurales de primaria

proceso, reflexionando sobre cuáles pueden ser los posibles caminos para que el desarrollo cognitivo se acelere y generen significaciones amplias y duraderas.

\section{Metodología}

Esta investigación se desarrolló bajo el enfoque cualitativo, un diseño fenomenológico y hermenéutico con un alcance descriptivo, y un método inductivo, de esta forma permitió indagar, conocer y de manera directa acercarse a la problemática planteada en este trabajo, a través de la aplicación de diferentes instrumentos que llevan al estudio de la realidad académica de los estudiantes del grado $5^{\circ}$ de la escuela Rural Nicolás Esguerra, respecto a su rendimiento académico y los factores que en él tienen incidencia.

De la misma manera, la selección del enfoque cualitativo se sustenta en que este se ubica en el análisis de complejidades como lo expresan Hernández et al., (2014). El centro de interés abordado dentro del contexto social escolar que se propone en esta investigación alude a reconocer cómo dentro de las aparentes limitaciones que plantea el sistema escolar estándar, se pueden detectar posibles variables que permitan generar un diálogo entre la teoría de las inteligencias múltiples y las del desarrollo de la autogestión del aprendizaje, que conlleve a diseñar una estrategia didáctica que garantice el buen rendimiento académico para los niños y niñas de la institución en cuestión.

Se adopta el diseño fenomenológico puesto que este tiene como propósito central poder explorar y describir con mayor comprensión las particularidades vivenciales de los individuos alrededor de un fenómeno, para describir aspectos prioritarios de dichas vivencias (Hernández et al. 2014). Se selecciona teniendo en cuenta que el problema planteado en la presente investigación deja en evidencia las falencias comunes de los estudiantes del grado quinto de la Escuela Nicolás Esguerra frente a sus prácticas autorregulatorias, lo que conlleva a obtener bajos resultados académicos. Además, se hace relevante conocer desde la experiencia de los estudiantes, maestros y padres de familia de este grado, los elementos comunes en los que coinciden los procesos implícitos en la enseñanza y su posible impacto en los resultados desfavorables que obtienen los estudiantes.

Para esta investigación cualitativa, se trabajó el método inductivo pues se plantea un razonamiento ascendente que fluye de lo particular o individual hasta lo general (Abreu, 2014, p. 200). Así entonces, se inició desde las particularidades de las situaciones a lo general, en el ejercicio docente y casos específicos sobre los que se evidencie un beneficio en relación al rendimiento académico de los estudiantes de este curso.

La unidad informante de estudio estuvo constituida por la comunidad estudiantil de la zona rural del Municipio de Ibagué, Tolima, Colombia, de la Institución Educativa Técnica Ambiental Combeima, sede Nicolás Esguerra, jornada única, para un total de 645 estudiantes distribuidos en preescolar, básica primaria, básica secundaria y media. De manera más específica, se determinó que de los 18 niños y niñas de grado $5^{\circ}$ participaran 13 estudiantes, 7 niños y 6 niñas con edades que oscilan entre los 9 y 10 años. También la conformaron los padres de familia de los estudiantes mencionados y cuatro maestros que trabajan en el grupo. 
Para el desarrollo de esta investigación se trabajó bajo tres categorías (Ortiz y Contreras, 2018), a saber: estrategias didácticas de aprendizaje, inteligencias múltiples (IM) y autorregulación, cada una con sus respectivas subcategorías de análisis: 1. Estrategias didácticas; rendimiento académico, propósitos de aprendizaje, formación docente, interacción con otros agentes educativos, recursos educativos, pertinencia de los diseños curriculares, elementos didácticos, estilos de aprendizaje, mediación pedagógica, mediación tecnológica, innovación en el aula, ideas previas, ambientes de formación y evaluación de los aprendizajes. 2. Inteligencias múltiples; concepto de inteligencia, decisiones determinantes en la formación, escenarios para el desarrollo de la inteligencia, medio sociocultural, genética, educación, formación integral, tipos de inteligencia, caracterización de las inteligencias y aprendizaje e inteligencias múltiples. 3. Autorregulación; concepto de autorregulación, prácticas autorregulatorias, factores de la autorregulación, motivación, agentes externos en la autorregulación, principales actores, administración y planeación, fases en la autorregulación, objetivos de la autorregulación y secuencia didáctica.

Desde el enfoque cualitativo, el acopio de datos como técnica, está definida en relación con la recolección de información en contextos naturales y del diario vivir de los que participan o sus referentes a analizar. Además, con respecto al cuestionario, se describe como preguntas que propenden por dar respuestas a determinadas categorías objeto de análisis y que debe poseer una relación directa con la problemática a abordar. Respecto a la entrevista semiestructurada, se señala como una orientación de elementos interrogatorios donde quien, entrevista, posee la facultad de generar nuevas preguntas para dar precisión a ideas y conseguir información adicional (Hernández et al., 2014). De este modo, se utilizó para la presente investigación los cuestionarios y la entrevista semiestructurada y esta recolección se llevó a cabo en el contexto escolar de modalidad eminentemente virtual y telefónica como espacio de encuentro, debido a la contingencia generada por la emergencia sanitaria generada por la COVID-19.

También se realizó una validación de contenido de los tres instrumentos tipo formulario web y la entrevista semiestructurada por cuatro expertos, quienes pusieron a disposición sus conocimientos disciplinares y metodológicos relacionados y con una vasta experiencia como investigadores para reivindicar la claridad, veracidad, coherencia, viabilidad y confiabilidad de los instrumentos. Vía telefónica se les indicó a los actores participantes en qué consistía el ejercicio y a través de un consentimiento informado se le dio vía libre a la aplicación de los mismos los cuales, dadas las situaciones de contingencia producida por la emergencia sanitaria de la COVID-19, se debió realizar usando medios virtuales digitales, sistematizados y computacionales.

\section{Resultados}

Esperando alcanzar los objetivos que desde el inicio se trazaron para esta investigación, se recolectó la información derivada de las respuestas a los instrumentos aplicados a las tres fuentes de información escogidos. Los formularios web se elaboraron sobre la herramienta Forms de Google y la información digital de estos se administró por medio de Excel. Así entonces, se obtuvo matrices de datos confiables para poder analizar e interpretar a la luz de la pregunta de investigación. A continuación, se presentan los resultados obtenidos. 


\section{Estrategias didácticas de aprendizaje}

El constructo de estrategias didácticas constituye los elementos propositivos e intencionados con los que cuenta un docente para encaminar la enseñanza directamente hacia el aprendizaje significativo por medio de los recursos dispuestos en el contexto educativo, la experiencia con que cuenta y las características particulares de los estudiantes y lo que estos como grupo llegan a representar. Esto se evidencia en la tabla 1.

\section{Tabla 1}

Hallazgos en la categoría de estrategias didácticas

\section{Estrategias didácticas de aprendizaje \\ Mediación pedagógica}

Recursos educativos: El inventario de recursos que realiza el docente durante la planeación es determinante en el impacto que genera una estrategia de aprendizaje.

Elementos didácticos: La evaluación de los logros alcanzados en la práctica docente debe ir acompañada por la revisión de la selección de los medios didácticos y su pertinencia.

Interacción pedagógica: La relación entre lo que se pretende enseñar y lo que el estudiante aprende está mediada por los agentes educativos y el rol que cada uno desempeña.

Medios tecnológicos: El uso de medios tecnológicos más que una obligación por el contexto educativo y la presión que por este pueda existir, debe responder a las necesidades propias de conjunto temario a desarrollar con los estudiantes.

\section{Evaluación educativa}

Rendimiento académico: La respuesta dada por los estudiantes frente a las propuestas didácticas, también permiten determinar el nivel de resultados en un periodo determinado.

Contenidos educativos y contexto: Un factor motivacional y que da cuenta del éxito en la estrategia tiene que ver con la relación de los estudiantes con su realidad.

Formas de evaluar: Independientemente de cómo se evalúe, el enfoque debe apuntar a la construcción del estudiante en sus dimensiones académica y personal.

Fuente: Elaborado por los autores.

En el transcurso de la investigación desarrollada con los estudiantes de grado quinto de la Escuela Rural Nicolás Esguerra, y luego de la aplicación de los instrumentos, se encontraron diferentes hallazgos que estructuraron las respuestas a las preguntas planteadas y a dar cuenta de los objetivos. Es por eso que, en este apartado se presentan los resultados más relevantes con los 
cuales se evidencia el impacto del estudio y se abre la puerta a nuevas posibilidades de profundización en los temas centrales y posibles nuevos hallazgos.

Respecto a los recursos educativos, la preferencia de la mitad de los docentes está orientada hacia el uso de las tecnologías de información y la comunicación. Otro opta por el uso de material físico y el último, se inclina por la combinación de ambos recursos, lo que significa que, en general, los profesores están alineados con las exigencias del contexto educativo actual y las condiciones sociales en las que están inmersos los estudiantes. De la misma manera, este grupo de maestros, en el uso de los elementos didácticos, trabaja de la mano con lo que hay a su disposición por parte de la institución enlazados con los objetivos del aprendizaje. Esto se evidencia en la figura 1.

\section{Figura 1}

\section{Mediaciones pedagógicas}

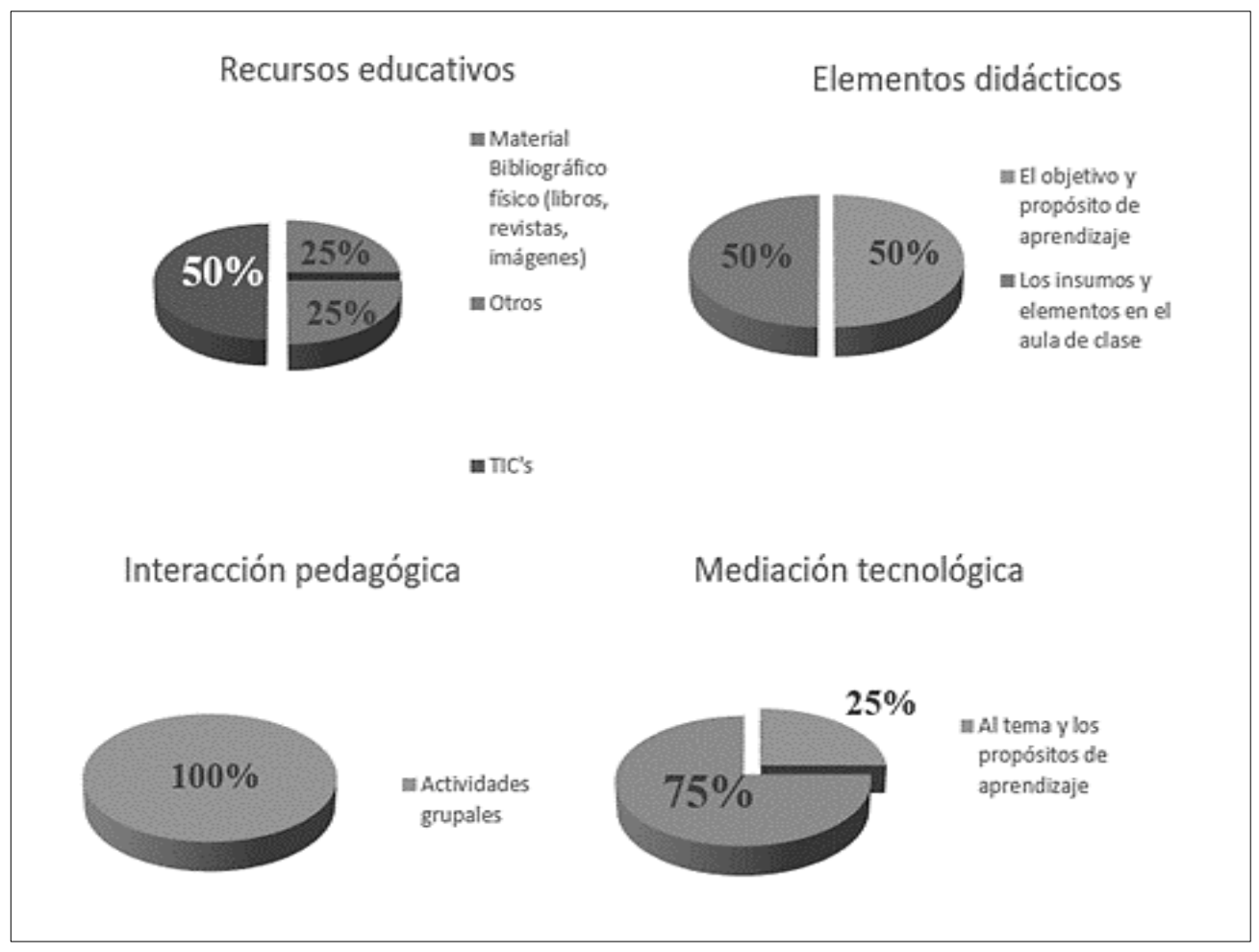

Respecto al constructo de la evaluación educativa, se resalta, en primer lugar, la valoración por parte de tres de los profesores del rendimiento académico basándose en la participación activa de los estudiantes durante su aprendizaje y el otro docente, en las calificaciones, lo que da cuenta de unas prácticas evaluativas basadas en los resultados. De la misma manera, se halla que dos maestros optan por acercar los estudiantes a los contenidos educativos a través de ejercicios de reflexión a partir de los temas vistos y dos maestros lo hacen a través de un continuo contraste entre la cotidianidad de los alumnos y los conceptos a estudiar, lo que tiene que ver con las características propias de la evaluación diagnóstica. Esto se evidencia en la figura 2. 
Estrategia didáctica de aprendizaje basada en inteligencias múltiples predominantes y procesos autorregulatorios en estudiantes rurales de primaria

\section{Figura 2}

Evaluación educativa

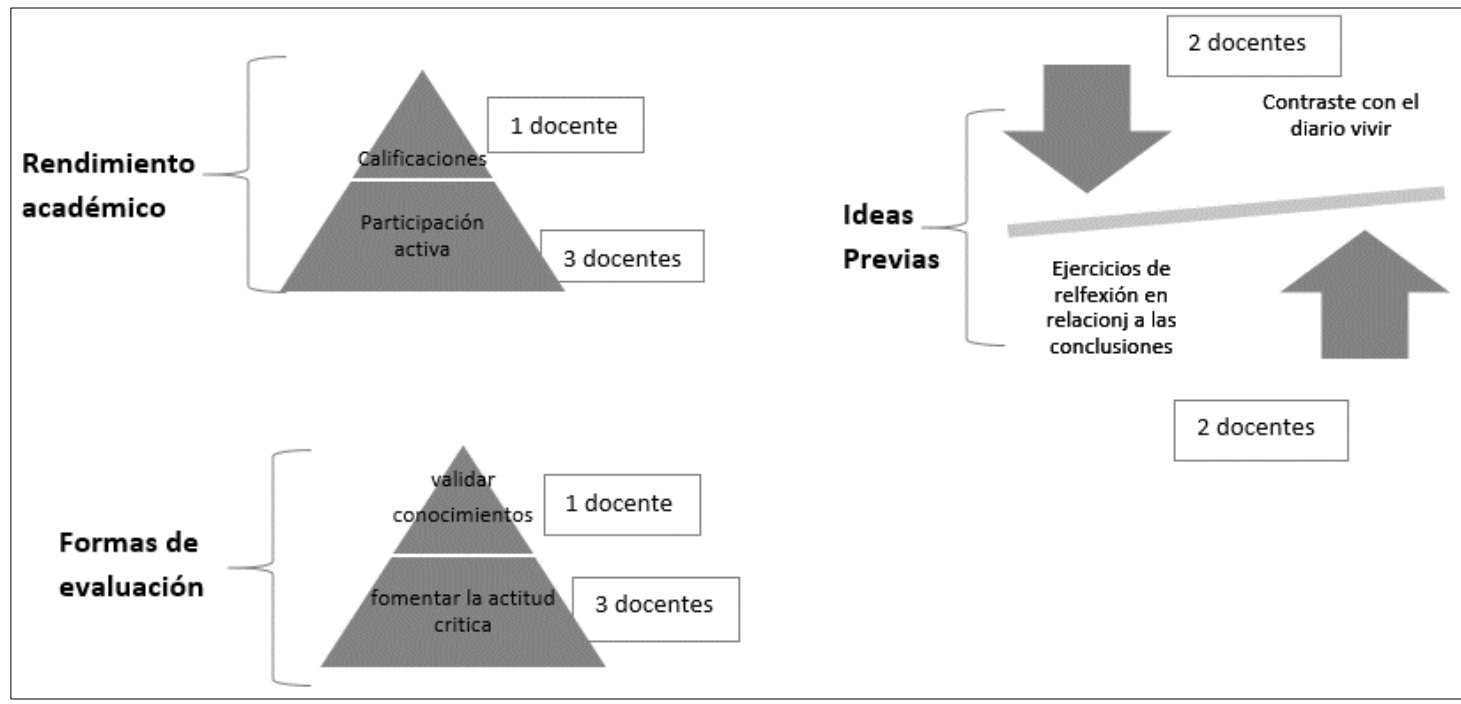

\section{Inteligencias múltiples}

La Teoría de las Inteligencias Múltiples de Gardner (1983), plantea que la inteligencia no es unidireccional sino multifacética y que en concreto son ocho tipos las cuales, combinadas entre sí, determinan el perfil intelectual de un individuo. Además, afirma que si se cultivan con eficiencia pueden generar valiosos resultados en los procesos de aprendizaje. Esto se evidencia en la tabla 2.

\section{Tabla 2}

Hallazgos en la categoría de inteligencias múltiples

\section{Inteligencias múltiples}

\section{Inteligencia y medio sociocultural}

Escenarios para el desarrollo de la inteligencia: El entorno sociocultural juega un papel fundamental como elemento mediador para el desarrollo de la inteligencia en los estudiantes.

\section{Tipos de inteligencia}

Las inteligencias en contexto: Las inteligencias múltiples se encuentran internalizadas en una determinada proporción en los contextos educativos y es posible evidenciarse a partir de la indagación de variables que conducen a su descubrimiento.

\section{Caracterización de las inteligencias múltiples}

Combinación de inteligencias: El perfil intelectual es el resultado de la integración de todas las inteligencias múltiples por lo que ello representa una visión no lineal sino holística de la inteligencia.

Fuente: Elaborado por los autores. 
Respecto a las IM (Inteligencias Múltiples), se obtiene que la mayoría del grupo posee las inteligencias Ecológica e Interpersonal de manera predominante, $42 \%$ y $19 \%$ respectivamente, teniendo en cuenta que el contexto físico y ambiental condicionan el desarrollo de la inteligencia, pues los estudiantes hacen parte de una zona rural con gran afluencia de turistas. En función a los datos recolectados, se observa la diversidad de las inteligencias presentes en los integrantes de grado $5^{\circ}$, lo que permite pensar en el potencial de aprendizaje que posee el grupo estudiado. Esto se evidencia en la figura 3.

\section{Figura 3}

\section{Inteligencias múltiples predominantes}

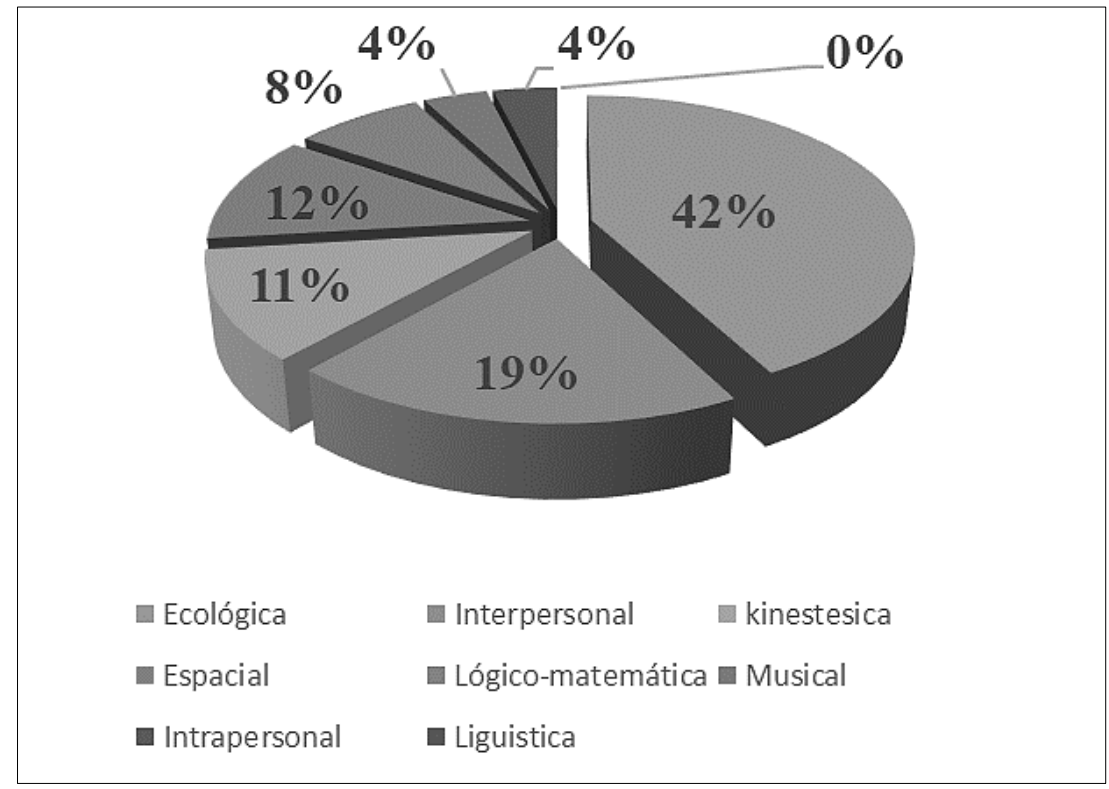

Se presenta como hallazgo, la caracterización del perfil intelectual del grupo, indicando que las habilidades presentes en él posibilitan la formulación de proyectos institucionales que apunten al desarrollo de aprendizajes que integren el medio ambiente y la interacción social. Además, genera importantes reflexiones sobre la necesidad de impulsar estrategias académicas que fortalezcan áreas como las matemáticas, el lenguaje y campos vocacionales como la música. Esto se evidencia en la figura 4. 
Estrategia didáctica de aprendizaje basada en inteligencias múltiples predominantes y procesos autorregulatorios en estudiantes rurales de primaria

\section{Figura 4}

Caracterización de las inteligencias múltiples

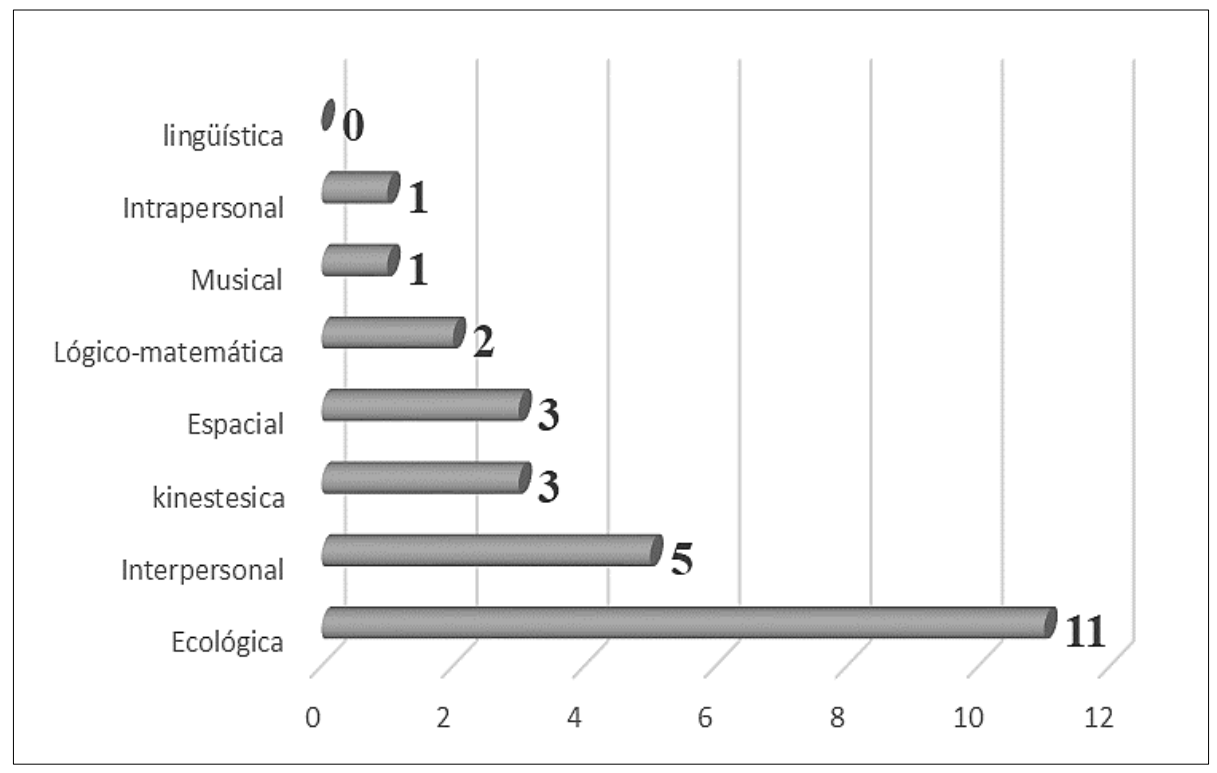

\section{Proceso de autorregulación del aprendizaje}

La autorregulación en el aprendizaje está compuesta por habilidades de control que se relacionan con los pensamientos, acciones, emociones y motivaciones del mismo individuo. Lo mencionado anteriormente, lleva al alumno a enlazar estrategias personales y a generar una mayor metacognición, con el propósito de alcanzar los objetivos fijados por él mismo. En el desarrollo de la autorregulación se evidenciará un cambio o ajuste sobre los factores intrínsecos y en menor medida, sobre los factores extrínsecos. Así se entiende que el estudiante es un agente activo en el desarrollo de su proceso de autogestión. Esto se evidencia en la tabla 3.

\section{Tabla 3}

Hallazgos en la categoría de autorregulación

\section{Proceso de autorregulación del aprendizaje}

\section{Motivación}

Acciones motivacionales: Evidencia del ánimo para con el proceso de aprendizaje.

\section{Organización de los procesos de autorregulación}

Mejorar planificación: Etapa de planificación susceptible de mejora.

Diligencia y esmero en pro de la organización: Evidencia de autocontrol y orden en la etapa de ejecución.

Cierre débil del proceso: Mayor ejercicio en la etapa de Auto-reflexión.

Fuente: Elaborado por los autores. 
Cuando se evalúan las respuestas de los tres grupos participantes en el diligenciamiento de los formularios web de encuesta, el hallazgo más significativo fue que los estudiantes, vistos como conjunto, presentan actitudes que dan testimonio de esa motivación, motor que se requiere siempre en acción para sostenerse en el ejercicio autorregulatorio. Esta evidencia se presenta con un 52\% con relación a las acciones propias de motivación y un 58\% de compromiso con su desempeño como se muestra en la figura 5.

Así desde la perspectiva docente y/o desde el ambiente de la institución, se tiene sobre la media, evidencia del ánimo de los estudiantes para con el aprendizaje, lo que contrasta con la opinión personal del alumno y el ambiente familiar en el que se muestran mayores acciones que dan cuenta de la motivación del educando.

\section{Figura 5}

\section{Motivación}

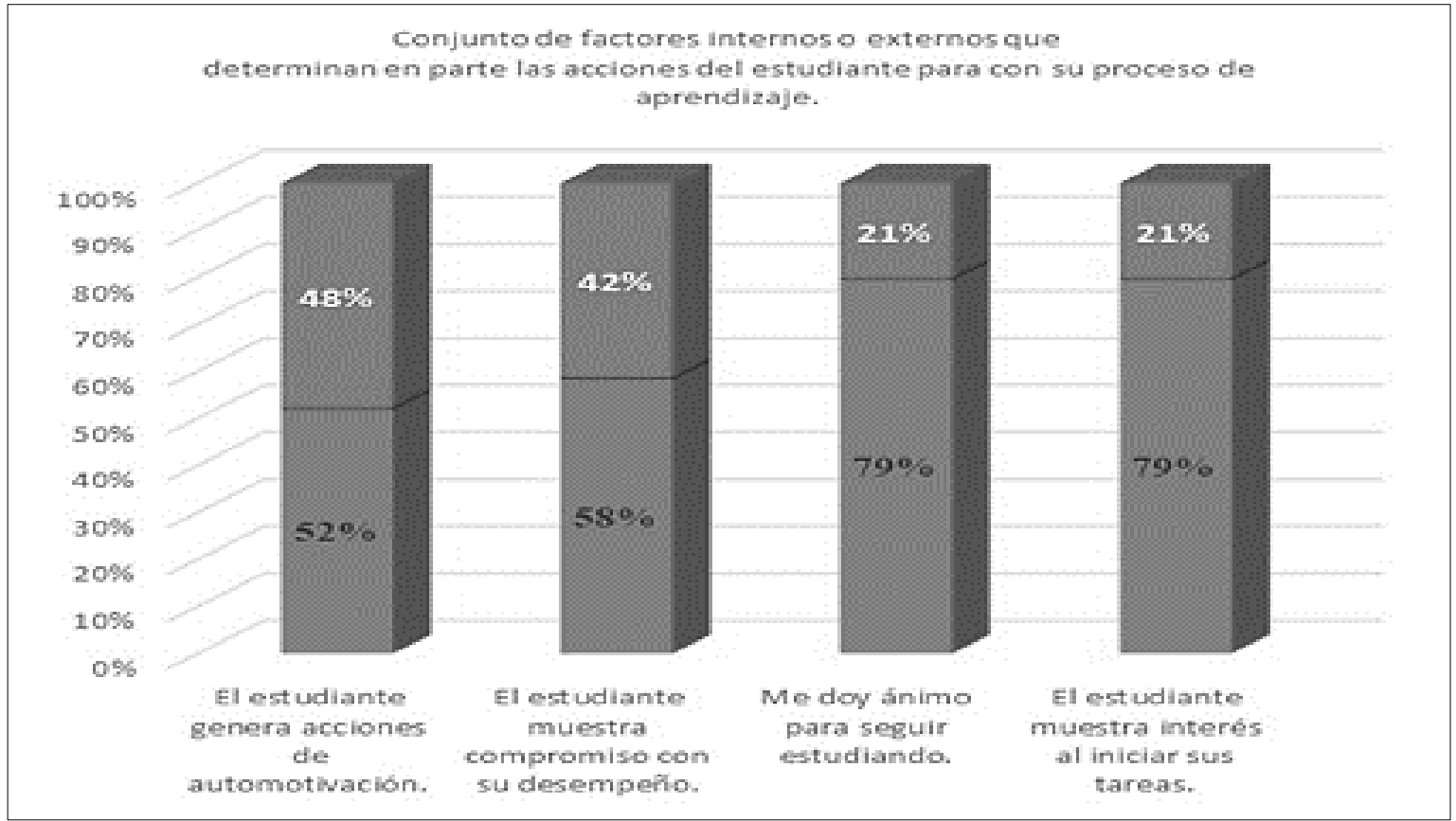

Por otro lado, el hallazgo presentado en la figura 6 en función a los resultados es que el grupo sujeto de estudio desarrolla mayores acciones de autorregulación en la etapa de ejecución y en menor grado en la fase de autorreflexión. Lo anterior sugiere una mayor actividad metacognitiva del grupo cuando se encuentran desarrollando las acciones planteadas por los docentes, pero una gran debilidad a la hora de evaluarse a sí mismos al final del proceso de aprendizaje. Esto se evidencia en la figura 6 . 
Estrategia didáctica de aprendizaje basada en inteligencias múltiples predominantes y procesos autorregulatorios en estudiantes rurales de primaria

\section{Figura 6}

Organización de los procesos de autorregulación

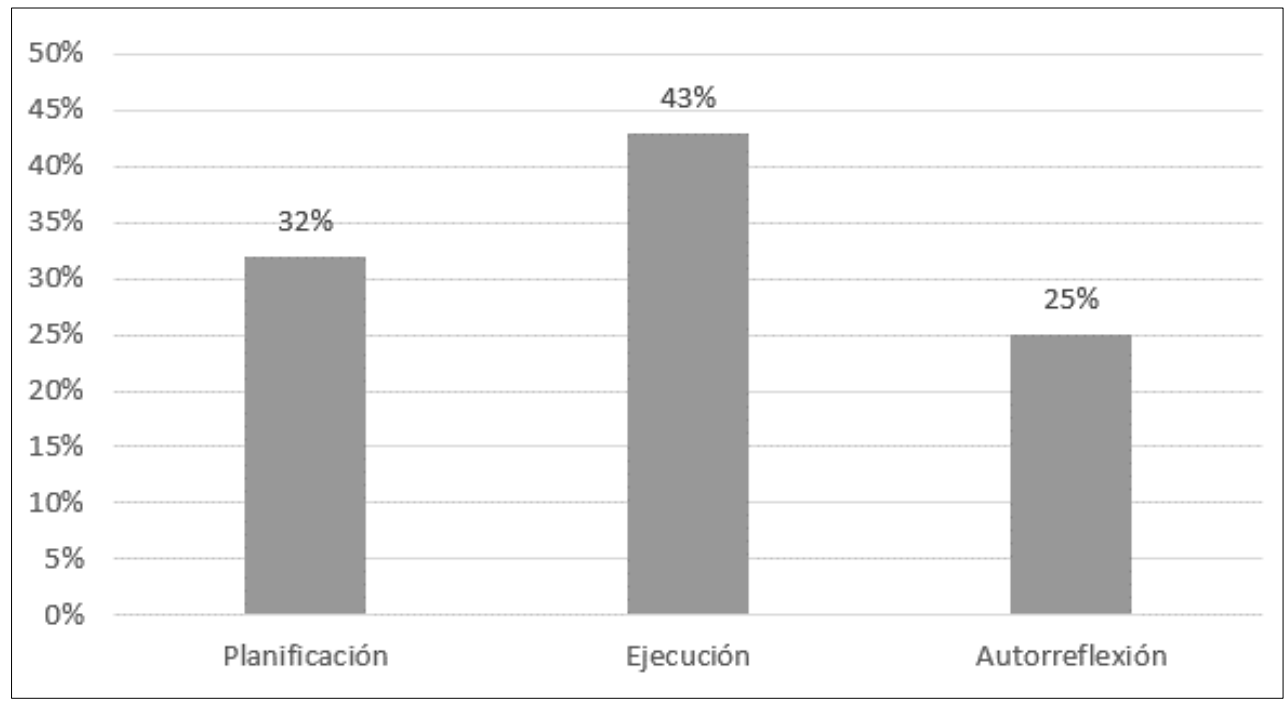

\section{Inteligencias múltiples y autorregulación}

A partir de las respuestas planteadas por el docente entrevistado, se pueden analizar las inteligencias múltiples y los procesos de autorregulación expresados de varias maneras. En primer lugar, esta relación puede generar planes de acción que reconozcan las diferencias individuales de los integrantes del curso. Además, brinda herramientas al docente y al estudiante para realizar de forma adecuada las diferentes actividades. En este mismo sentido, cuando el educando se siente reconocido y motivado mientras trabaja, se genera en él mejores respuestas, y, por ende, se dinamiza el proceso educativo y se obtienen resultados muy positivos.

Por otro lado, es importante destacar que se mejoran los ambientes de trabajo en el aula, el alumno está más atento a recibir las instrucciones y/o el conocimiento y de la misma forma, a ser un agente propositivo y participativo de su proceso. Finalmente, otras relaciones que se pueden establecer indican que el docente que reconoce la Inteligencia Múltiple del grupo tiene mayor impacto en ellos y se crean lazos de afectividad, pues se tiene un mayor conocimiento del recurso humano lo que permite potenciar sus aptitudes. Desde el punto de vista pedagógico, se fortalece la gestión y el uso de herramientas para el diseño de prácticas de enseñanza, se propende por el uso de nuevas metodologías y hay un mayor empoderamiento del estudiante frente a su desempeño. Esto se evidencia en la figura 7. 


\section{Figura 7}

\section{Inteligencias múltiples y autorregulación}

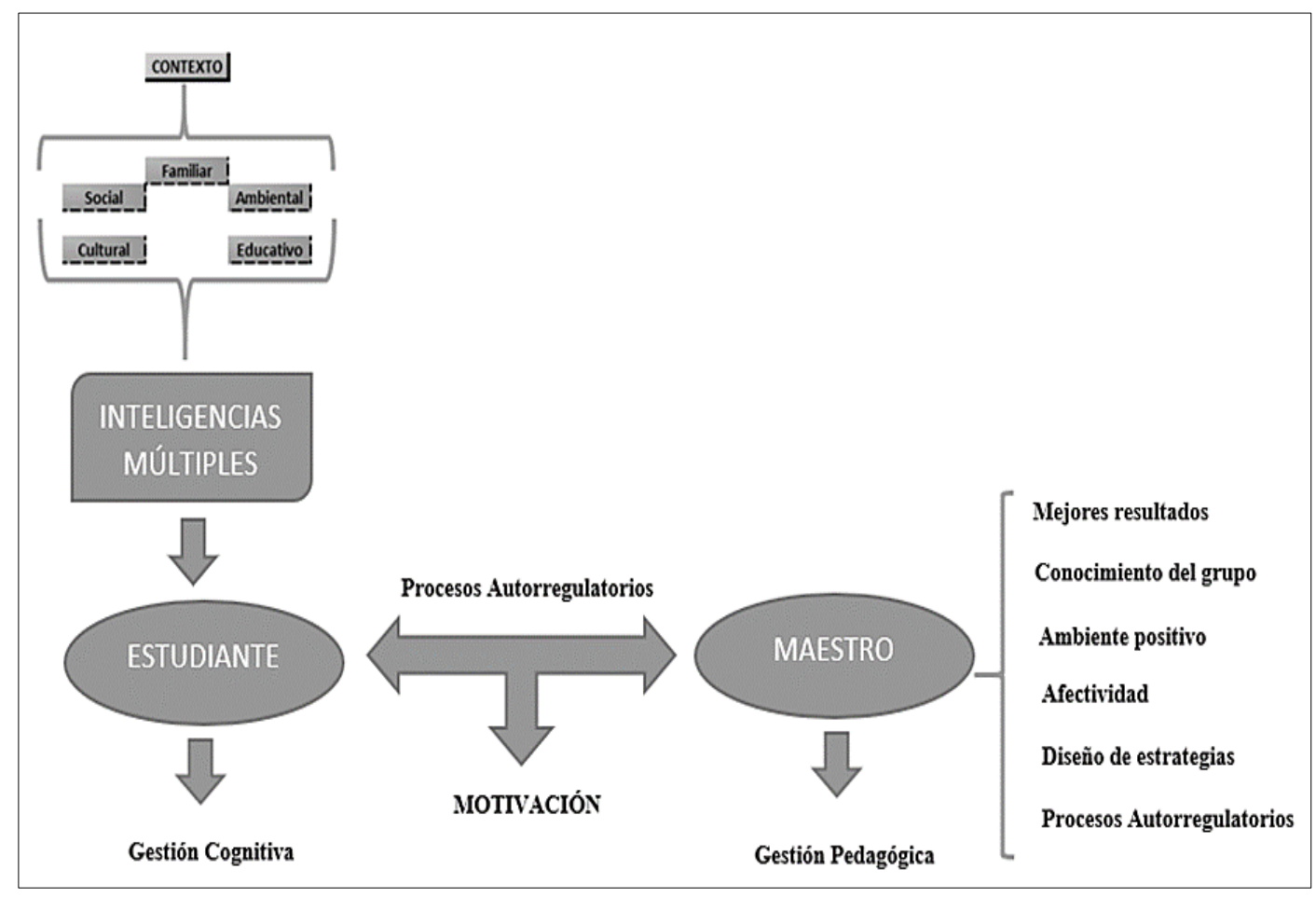

A partir de los resultados, se plantea una estrategia didáctica transversal la cual constituye una herramienta pedagógica que como se expresa desde los lineamientos del Ministerio de Educación Nacional, propende por el fortalecimiento de las competencias y acciones pedagógicas, las cuales, al integrar saberes, se convierten en praxis para la vida (Ministerio de Educación Nacional MEN, 2014).

Además, este tipo de diseño no es ajeno a lo planteado por la ley 115 donde se destaca claramente la posibilidad de que las instituciones educativas de Colombia, basados en derechos de autonomía, puedan reajustar la organización de las áreas fundamentales de cada nivel, introducir asignaturas optativas y generar adaptaciones que respondan a las necesidades contextuales (Ministerio de Educación Nacional, 1994).

Al haberse identificado las inteligencias Ecológica e Interpersonal como predominantes en el grupo investigado, se determinó que debía ser con estas categorías desde donde se podrían generar los procesos de transversalización. Por lo anterior, se realizó una lectura de los Derechos Básicos de Aprendizaje (DBA) de las asignaturas en cuestión y se encontró una afinidad con las distintas áreas del conocimiento como se evidencia en la tabla 4. 


\section{Tabla 4}

Inteligencias y distribución del plan de estudio

\section{Inteligencias}

\section{Inteligencia Naturalista}

Eje: Naturaleza y medio ambiente

Asignatura: Ciencias naturales, Ecoturismo, Ciencias Sociales, Educación física, Artística; Matemáticas

Herramienta Pedagógica: La huerta escolar

\section{Inteligencia Interpersonal}

Eje: Sociedad y comunicación

Asignatura: Castellano, Ética y valores humanos, Informática, Ingles, Religión.

Herramienta Pedagógica: El noticiero

Fuente: Elaborado por los autores.

Es importante plantear otros elementos a esta estrategia didáctica que necesariamente afectarían el diseño curricular en la institución. En primera medida, se establecieron dos ejes de formación para trabajar para cada inteligencia y la herramienta pedagógica de cada una, como lo expresa la tabla 4. Como producto de la investigación y sus resultados, se determinó que los proyectos a entregar con base en las inteligencias preponderantes fueran la construcción de la huerta escolar y la puesta en escena de un noticiero tipo magazine. Los demás elementos del diseño curricular para la inteligencia naturalista que se proponen, se encuentran en la tabla 5. En el caso del diseño para la otra inteligencia, se propone el mismo modelo, realizando los ajustes al contenido.

\section{Tabla 5}

Propuesta de diseño curricular para transversalización

\begin{tabular}{cl}
\hline Elementos & Propuesta de diseño curricular \\
\hline Estructura & Inteligencia: Naturalista \\
Eje de formación: Naturaleza y Medio Ambiente \\
Semestre: Primero \\
Áreas Participantes: Ciencias naturales, Ecoturismo, Ciencias \\
\\
Sociales, Educación física, Artística; Matemáticas \\
Grado: $6^{\circ}$ \\
Herramienta Pedagógica: La Huerta Escolar \\
Perfil del Estudiante: El estudiante comprende la naturaleza \\
desde la dimensión de relevancia y preservación.
\end{tabular}




\begin{tabular}{cc}
\hline Elementos & Propuesta de diseño curricular \\
\hline Objetivos & $\begin{array}{c}\text { Contextualizadores: Identifica... } \\
\text { Fundamentadores: Explica... } \\
\text { Pragmáticos: Realiza... } \\
\text { Reflexivos: Evalúa... }\end{array}$ \\
$\begin{array}{c}\text { Pregunta } \\
\text { Problematizadora }\end{array}$ & $\begin{array}{c}\text { ¿Qué características tiene el medio natural que rodea la } \\
\text { institución? } \\
\text { ¿Cómo interactúan los elementos bióticos y abióticos con el }\end{array}$ \\
& medio físico de la institución? \\
& ¿De qué manera se puede construir una huerta escolar? \\
& ¿Qué importancia tiene para el medio ambiente y el desarrollo \\
& sostenible las huertas escolares? \\
Competencia & Realizo planes de búsqueda que incluyan posibles fuentes \\
& primarias y secundarias para encontrar información que conteste a mis \\
preguntas. & Nota: Las tres competencias restantes serán desarrolladas de \\
& acuerdo a los objetivos planteados. \\
Producto & Entrega del proyecto de siembra en su etapa de observación. \\
& Presentación oral y escrita de avances del proyecto. \\
Criterios de & Argumenta de forma clara y precisa sus ideas \\
Evaluación &
\end{tabular}

Para conseguir una adecuada transversalización, esta propuesta explica las diferentes etapas del proceso de implementación en la figura 8. Inicialmente, se debe nombrar un equipo pedagógico líder que se encargará de direccionar todas las etapas del proceso. Dicho equipo debe ser escogido de acuerdo a una alta formación académica (especialización, maestría o doctorado hasta donde lo posibiliten las condiciones del talento humano de la institución), para lograr un significativo impacto en la comunidad educativa. Luego se socializa el proyecto con el cuerpo docente, para después pasar a formar los dos grupos focales (uno para cada inteligencia) conformado por los docentes que dictan las asignaturas que se integrarán con una de ellas.

Estos dos grupos focales deben seleccionar las competencias, Derechos Básicos de Aprendizajes y contenidos que deben priorizarse para articularlos al proyecto, y a partir de ellos, generar el diseño y contenido de esa nueva estructura curricular. Los contenidos disciplinares que no logren la afinidad con el proyecto de transversalización, se dictan de manera paralela como es tradicional. Las tres últimas etapas están relacionadas con la socialización a los estudiantes y padres de familia de grado $6^{\circ}$ (sexto) del proyecto, la implementación y finalmente la evaluación del impacto del mismo. Este último se realiza a partir de las evaluaciones tanto internas como externas del año de ejecución del proyecto. Esto se describe en la figura 8. 
Estrategia didáctica de aprendizaje basada en inteligencias múltiples predominantes y procesos autorregulatorios en estudiantes rurales de primaria

\section{Figura 8}

Fases del proceso del proyecto transversal

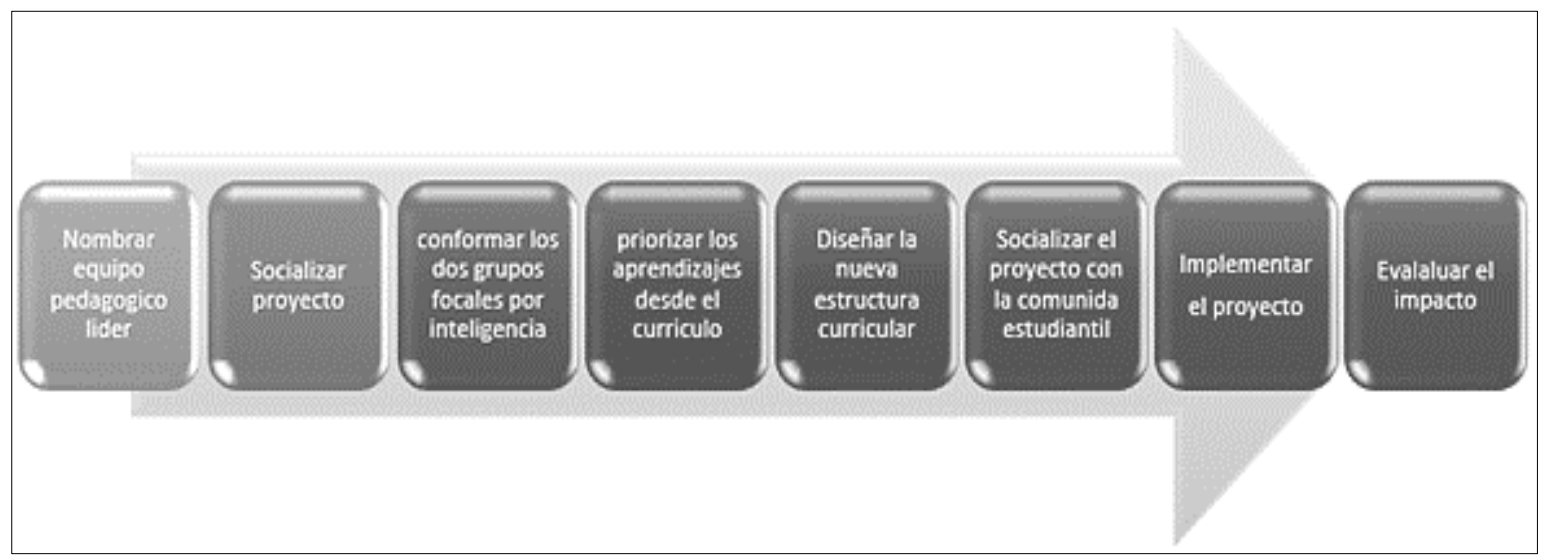

En la evaluación de los estudiantes no solo se realizan la hetero-evaluación, sino que también se propone una autoevaluación en los diferentes procesos del aprendizaje desde una matriz de autorregulación en sus tres fases (antes, durante y al finalizar la actividad), la cuales están basadas en los hallazgos en las prácticas autor-regulatorias de este grupo. Se propone una matriz para el maestro y otra para cada estudiante.

\section{Conclusiones}

Los hallazgos anteriormente referenciados conducen a observar que la motivación, motor indispensable en el proceso de aprendizaje, está presente en la gran mayoría de los individuos del grupo, lo cual permite al docente implementar y desarrollar con éxito la planeación. Además, se observa que los estudiantes presentan mayores niveles de autorregulación en la fase de ejecución y en la que más requieren acompañamiento es en la fase de autorreflexión.

Se determina que una vez conocidas las Inteligencias Múltiples predominantes es más factible para el docente apropiar herramientas pedagógicas con un mejor enfoque, permitiéndoles ajustarlas desde el momento de la planeación, hasta la propia ejecución en los ambientes de aprendizaje, potenciando y reforzando de esta forma las habilidades según el tipo de aprendizaje, mayor atención a la diversidad y el fomento en la innovación.

De la misma forma, se puede afirmar que al existir una correlación entre las Inteligencias Múltiples predominantes como lo son la ecológica e interpersonal con el contexto físico habitacional y ambiental, se pueden generar acciones que evidencien motivación, confianza y compromiso con el proceso de aprendizaje ya que más de la mitad de los estudiantes demuestra acciones de planificación y ejecución afectivas cuando se encuentran motivados e interesados por su aprendizaje.

Con respecto a las estrategias didácticas de aprendizaje, se concluye que la mitad de los docentes espera formar a sus estudiantes con capacidad crítica frente a la sociedad en que viven, promoviendo la participación activa por encima de las notas obtenidas al final de un periodo 
académico. De la misma manera, la mitad de los docentes prefiere el uso de las TIC en la ejecución de los contenidos de clase y en contraposición a esto, la mitad de los docentes prefieren actualizarse frecuentemente en temas relacionados con el componente pedagógico.

Es relevante la importancia que para los maestros tiene el ambiente de aprendizaje, porque condiciona la planeación pedagógica, teniendo presente las competencias de los estudiantes. Las inteligencias evidenciadas en el grupo, en interacción con las estrategias, convierten el aula de clase en un elemento mediador para favorecer los procesos pedagógicos y académicos.

Desde un punto de vista holístico, resulta pertinente plantear que el contenido de este artículo es una fuente de análisis científica que permite determinar, a la luz de las perspectivas teóricas y de una puesta en práctica de las mismas, que se pueden dar alternativas de solución pedagógicas a fenómenos educativos, pues esta investigación resalta el valor que se aporta a la educación desde distintos enfoques: la transversalidad, la integración curricular, la innovación, la democratización de los procesos de enseñanza-aprendizaje, el uso eficiente de la metacognición y la potencialización de recursos cognitivos que disponen los estudiantes, lo cual redunda en una aportación a la calidad educativa. Los anteriores planteamientos combinados con otras unidades investigativas de análisis, enriquecen el debate al respecto y generan la posibilidad de producir nuevos hallazgos científicos.

\section{Referencias bibliográficas}

Abreu, J. (2014) El método de la investigación. Daena: International Journal of Good Conscience. 9(3)195-204. p.1-10. http://www.spentamexico.org/v9-n3/A17.9(3)195-204.pdf

Abreu, O., gallegos, M. C., Jácome, J. G., y Martínez, R. J. (2017). La Didáctica: Epistemología y Definición en la Facultad de Ciencias Administrativas y Económicas de la Universidad Técnica del Norte del Ecuador. Formación universitaria, 10(3), 81-92. http://doi.org/10.4067/S0718-50062017000300009

Álvarez, J. (2003). Análisis de un modelo de educación integral [Tesis doctoral, Universidad de Granada]. https://digibug.ugr.es/handle/10481/4438

Ardila, R. (2011). Inteligencia ¿qué sabemos y qué nos falta por investigar? Revista de la_Academia Colombiana de Ciencias Exactas, Físicas y Naturales, 35(134), 97-103. http://www.scielo.org.co/scielo.php?script=sci_arttext\&pid=S0370-39082011000100009

Argüelles, D. y Nagles, N. (2009). Estrategias para promover procesos de aprendizaje autónomo. EAN Ediciones.

Armstrong, T. (2017). Inteligencias múltiples en el aula. Guía práctica para educadores. Ediciones Paidós.

Asensio, M. (2015). El aprendizaje natural, la mejor vía de acercarse al patrimonio. Educativo Siglo XXI, 33(1), p.55. https://doi.org/10.6018/j/222501

Bestard, C., Cantillo, A., Torres, V., Soto, J., y Andrés, B. (2015). Inteligencia humana. Un acercamiento teórico desde dimensiones filosóficas y psicológicas. Revista Información Científica, $91(3)$, 577-592. http://www.revinfcientifica.sld.cu/index.php/ric/article/view/235 
Estrategia didáctica de aprendizaje basada en inteligencias múltiples predominantes y procesos autorregulatorios en estudiantes rurales de primaria

Blanco, A. V., y Amigo, J. C. (2016). El rol del docente en la era digital. Revista interuniversitaria de formación del profesorado, $\quad 86, \quad 103-114$. https://www.redalyc.org/pdf/274/27447325008.pdf

Candiotti, M. A. P. (2017). La autorregulación: Un horizonte de posibilidades. Educación, 23, 913. https://doi.org/10.33539/educacion.2017.n23.1163

Delgado F., M., y Solano G. A., (2011). Estrategias didácticas creativas en entornos virtuales para el aprendizaje. Actualidades Investigativas en Educación, 9(2). http://euaem1.uaem.mx/bitstream/handle/123456789/1538/estrategias.pdf?sequence=1\&i sAllow

Díaz, F., y Hernández, G. (2002). Estrategias docentes para un aprendizaje significativo (Vol. 2). McGraw-Hill.

Edel, R. (2003). El rendimiento académico: concepto, investigación y desarrollo. Revista Iberoamericana sobre Calidad, Eficacia y Cambio en Educación 1 (2), p. 1-16. https://www.redalyc.org/pdf/551/55110208.pdf

Espinosa, E. A. (2016). La formación docente en los procesos de mediación didáctica. Praxis; Santa Marta, 12, 90-102. https://doi.org/10.21676/23897856.1850

Fernández, A., y Mihura de Rosa, D. (2015). Inteligencias múltiples. Revista de educación, motricidad e investigación, 4, 1-12. http://rabida.uhu.es/dspace/handle/10272/11632

García, C., Castañeda, E., y Mancilla, J. M. (2018). Experiencia de innovación en el aula desde la autorregulación y los estilos de aprendizaje. Tendencias pedagógicas, 31, 137-148. https://dialnet.unirioja.es/servlet/articulo?codigo $=6383452$

Gardner, H. (1983). Inteligencias múltiples. La teoría en la práctica. Paidós.

Gardner, H. (2009, noviembre 26 -28). La educación del futuro. Escuela con visión [Ponencia]. $\mathrm{X}$ Congreso de escuelas católicas, Toledo, España. http://www2.escuelascatolicas.es/sitios/eventos/XCongreso/ponencias/4Ponencia_Gardne r.pdf

Guilar, M. E. (2009). Las ideas de Bruner: De la revolución cognitiva a la revolución cultural. Educere, 13(44), 235-241. http://ve.scielo.org/scielo.php?script=sci_arttext\&pid=S131649102009000100028

Gutiérrez, J. C. L., y Ones, I. P. (2018). ¿Por qué es necesaria una didáctica específica para la educación Superior? Revista Científica ECOCIENCIA, 5(1), 1-17. https://doi.org/10.21855/ecociencia.51.13

Hernández, R., Fernández, C. y Baptista, P. (2014). Metodología de la investigación. McGrawHill. http://observatorio.epacartagena.gov.co/wp-content/uploads/2017/08/metodologiade-la-investigacion-sexta-edicion.compressed.pdf

Houssaye, J. (1988). Le triangle pédagogique. Peter Lang. http://shs-app.univrouen.fr/Old_appli/civiic/archives/LE\%20TRIANGLE\%20PEDAGOGIQUE.pdf

Hurtado, P. A., García, M., Rivera, D. A., y Forgiony, J. O. (2018). Las estrategias de aprendizaje y la creatividad: Una relación que favorece el procesamiento de la información. Revista ESPACIOS, 39(17). http://www.revistaespacios.com/a18v39n17/18391712.html

Jadue J, G. (1997). Factores ambientales que afectan el rendimiento escolar de los niños provenientes de familias de bajo nivel socioeconómico y cultural. Estudios pedagógicos. 23, 75-80. https://doi.org/10.4067/S0718-07051997000100007

Klaus, A. (2013). Didáctica: una introducción panorámica y comparada. Itinerario Educativo. Revista de la Facultad de educación. Universidad de Antioquia: Medellín. https://dialnet.unirioja.es/descarga/articulo/6280204.pdf 
Ley General de Educación (1994). La autonomía escolar. Bogotá: MEN. https://www.mineducacion.gov.co/1759/articles-124745_archivo_pdf9.pdf

Martí, L (2017). Aplicación de la teoría de las inteligencias múltiples y sus efectos sobre el rendimiento y la motivación en alumnos de 4 y 5 de educación primaria. (Tesis Doctoral). Universidad de Alicante. España. https://rua.ua.es/dspace/bitstream/10045/72343/1/tesis_lucia_marti_quiles.pdf

Mercadé, A. (2019). Los 8 tipos de inteligencia según Howard Gardner: La teoría de las inteligencias múltiples. http://materialestic.es/transicion/apuntes/Los.8.tipos.de.inteligencia.segun.Howard.Gardn er.pdf

Ministerio de Educación Nacional de Colombia. MEN. (2014) Sentidos y retos de la transversalidad. Bogotá: MEN. https://www.mineducacion.gov.co/1621/articles156179 recurso_12.unknown

Montealegre, R. (2016). Controversias Piaget-Vigotsky en psicología del desarrollo. Acta Colombiana de Psicología, 271-283. https://actacolombianapsicologia.ucatolica.edu.co/article/view/986

Mora, C., Mahecha, J. y Conejo, F. (2020). Procesos de autorregulación del aprendizaje y desempeño académico en estudiantes de pregrado bajo la modalidad virtual. Cultura Educación y Sociedad, 11(2), 191-206. https://doi.org/10.17981/cultedusoc.11.2.2020.12

Oliveos, G. (2017). Investigación en educación: las inteligencias múltiples presentes en el perfil cognitivo de estudiantes de básica primaria de la ciudad de Valledupar (Tesis de maestría). Universidad del Norte, Valledupar. http://manglar.uninorte.edu.co/bitstream/handle/10584/7716/130311.pdf?sequence=1

Ortíz, J. A. R., y Contreras, M. C. B. (2018). Categorización de resúmenes de publicaciones científicas basada en similitud semántica. Pistas Educativas, 38(120), p. 1-17. http://www.itcelaya.edu.mx/ojs/index.php/pistas/article/view/636

Padilla, M. (2017). Guía Didáctica en Inteligencias Múltiples en Proceso Enseñanza Aprendizaje. Educación Inicial (Tesis de maestría). Universidad de Guayaquil, Guayaquil. http://repositorio.ug.edu.ec/handle/redug/27058

Panadero, E., y Tapia, J. (2014). Teorías de autorregulación educativa: Una comparación y reflexión teórica. Psicología Educativa, 20(1), 11-22. https://doi.org/10.1016/j.pse.2014.05.002

Páramo, P., Hederich, C., López, O., Sanabria, L. B., y Camargo, Á. (2015). ¿Dónde ocurre el aprendizaje? Psicogente, 18(34). https://dialnet.unirioja.es/servlet/articulo?codigo $=6113775$

Patrick, H., y Middleton, M. J. (2002). Turning the Kaleidoscope: What We See When SelfRegulated Learning is Viewed with a Qualitative Lens. Educational Psychologist, 37(1), 27-39. https://doi.org/10.1207/S15326985EP3701_4

Piaget, J. (1981). Seis estudios de a psicología. Six Barral, S.A.

Pintrich, P. R. (2000). The role of goal orientation in self-regulated learning. In Handbook of selfregulation. Academic Press. https://doi.org/10.1016/B978-012109890-2/50043-3

Prada, et al., (2018). Inteligencias múltiples y rendimiento académico del área de matemáticas en estudiantes de educación básica primaria. Infancias Imágenes, 17(2), 163-175. https://doi.org/10.14483/16579089.12584

Recio, A. (2019). BreakoutEdu: el juego serio como estrategia para mejorar las habilidades de la competencia básica "aprender a aprender". Su incidencia en la motivación intrínseca, la 
autorregulación, la metacognición y el trabajo cooperativo del alumnado de Educación primaria de la Escuela Lumen de Terrassa. [Tesis de maestría, Universitat Oberta de Catalunya].

http://openaccess.uoc.edu/webapps/o2/bitstream/10609/99326/6/areciocrTFM0619memo ria.pdf

Schunk, Dale H. (2012). Teorías del aprendizaje. Una perspectiva educativa. México: Pearson. https://ciec.edu.co/wp-content/uploads/2017/06/Teorias-del-Aprendizaje-DaleSchunk.pdf

Seibane, C., Ferrero, G., y Gramundo, A. (2016). Saberes previos: su importancia en la promoción de aprendizajes [Conferencia]. I Jornadas sobre las Prácticas Docentes en la Universidad Pública. Transformaciones actuales y desafíos para los procesos de formación, La Plata, Argentina. http://sedici.unlp.edu.ar/handle/10915/61328

Sesento, L. (2017) Reflexiones sobre la pedagogía de Vigotsky. Revista Contribuciones a las Ciencias Sociales. https://www.eumed.net/rev/cccss/2017/02/vigotsky.html

Tuirán, A. P. (2016). Modelo pedagógico social cognitivo y su aplicación en las prácticas pedagógicas de docentes y estudiantes del programa de formación complementaria de la Institución Educativa Normal Superior de Sincelejo. Revista Educación y Pensamiento, 22(22). http://educacionypensamiento.colegiohispano.edu.co/index.php/revistaeyp/article /view/7

Valdivia, I. M. (2017). Evaluar para contribuir a la autorregulación del aprendizaje. Electronic Journal of Research in Education Psychology, 7(19), 1007-1030. https://doi.org/10.25115/ejrep.v7i19.1362

Valle, A. et al. (2006). Metas académicas, estrategias cognitivas y estrategias de autorregulación $\begin{array}{llllll}\text { del estudio. } & \text { Psicothema. } & 18 & \text { (2), } & \text { p. } & \text { 165-170. }\end{array}$ https://www.redalyc.org/pdf/727/72718201.pdf

Vigotsky, L. (1989). El desarrollo de los procesos psicológicos superiores. Crítica-Grijalbo.

Vivas, B. N. (2015). Las inteligencias múltiples como una estrategia didáctica para atender a la diversidad y aprovechar el potencial de todos los alumnos. Revista de Educación Inclusiva, 8(3), 121-136. https://dialnet.unirioja.es/servlet/articulo?codigo=5446538

Zimmerman, B.J. (2001). Theories of self-regulated learning and academic achievement: An overview and analysis. Lawrence Erlbaum Associates. https://www.tandfonline.com/doi/abs/10.1207/s15326985ep2501_2 